\title{
Behavioural changes after anaesthesia: Validity and liability of the Post Hospitalization Behavior Questionnaire in a Swedish paediatric population
}

\author{
MATS KARLING ${ }^{1}$, HANS STENLUND ${ }^{2}$ \& BRUNO HÄGGLÖF ${ }^{3}$ \\ Divisions of ${ }^{1}$ Anaesthesia, ${ }^{2}$ Epidemiology, and ${ }^{3}$ Child and Adolescent Psychiatry, University Hospital of Northern Sweden, \\ University of Umeå, Umeå, Sweden
}

\begin{abstract}
Aim: To study the validity and liability of a Swedish translation of the Post Hospitalization Behavior Questionnaire (PHBQ) in children in Sweden. Methods: The PHBQ was translated using a back-translation method. The subjects were 340 children, ages 2-13 y, admitted for elective surgery or diagnostic procedure with anaesthesia. The results were analysed using exploratory factor analysis with principal component analysis with Oblimin rotation. The fit to data was examined using confirmative factor analysis with a good measure of fit for the model ( $p>0.09$ for all factors). Results: Five factors emerged as being most consistent: general anxiety-withdrawal, eating disturbances, separation anxiety, regressionaggression and sleep anxiety. A panel of child psychologists confirmed the face validity of factors. Internal consistency (Chronbach's alpha) was adequate (0.75-0.87) for subscales and excellent for total score (0.93). Children less than 5 y old had higher scores than older children (mean $0.046 \pm 0.018$ vs $-0.0089 \pm 0.014, p<0.001$ ). There were no gender differences.
\end{abstract}

Conclusion: The results support a conclusion that a five-factor model better fits data from Swedish children than the original six-factor model.

Key Words: Behaviour, child, factor analysis, hospitalized, validation

\section{Introduction}

Hospitalization, illness and especially anaesthesia have been associated with changes in the behaviour of children. Many observers have described symptoms such as nightmares, eating problems and problems going to bed. In 1966, Vernon et al. developed a parent-rated instrument for quantifying and describing the symptoms in six different dimensions, called the Post Hospitalization Behavior Questionnaire (PHBQ) [1]. The PHBQ was developed from six studies concerning post-hospitalization behaviour, examining children who had been hospitalized and underwent anaesthesia and surgery during the 1950s. All symptoms mentioned in two or more of these studies were included in the questionnaire. The PHBQ consists of 27 items concerning sleep, eating, anxiety, aggressive behaviour, etc. For each item, the parent was asked to compare the child's current (posthospitalization) behaviour with the week before hospitalization. Five response alternatives were provided: "much less", "less", "unchanged", "more" and "much more" than before hospitalization. Each answer was given a score from 1 to 5 . Total score is calculated by adding all responses. Factor analysis made it possible to extract six subscales by grouping the items together. The subscales were: general anxiety and regression, separation anxiety, anxiety about sleep, eating disturbance, aggression towards authority, and withdrawal.

The instrument has been widely used to evaluate the results of different interventions, in order to minimize behavioural deterioration from stressful events and procedures during hospitalization $[2,3]$. These include experience with sedative premedication [4-7], psycho-educational preparation before procedures and surgery [8-12], day care versus inpatient care [13], type of anaesthesia induction [14], and parental presence at anaesthesia induction $[15,16]$. It has also been used to find predictors for changes in post-hospitalization behaviour, such as maternal or child anxiety prior to a procedure $[1-3,17-21]$.

Correspondence: Mats Karling, Department of Anaesthesia and Intensive Care, University Hospital of Northern Sweden, SE-901 85 Umeå, Sweden. Tel: +4690 7850000. Fax: +4690 136235. E-mail: mats.karling@vll.se 
Whether or not the influence of different hospital routines had any impact on behaviour has also been tested [22].

Psychometric properties have been studied, and reliability and validity have been shown [1]. The stability over time was tested on 37 children undergoing cardiac catheterization. Parents completed the questionnaire after $3 \mathrm{~d}$ and after 1 mo. The total scores from these two occasions were significantly related. This questionnaire had two items omitted and had only three response alternatives [23].

The validity was tested by comparing the total score from the questionnaire with ratings done by a child psychiatrist who interviewed 20 children 1 wk after tonsillectomies $(r=0.45, p<0.05)$ [1]. The ratings were confirmed by a child psychologist who analysed the interview from tape recordings. To test whether the parental style for completing the questionnaire introduced bias into the score, a comparison was made for the scores for three groups of children who underwent tonsillectomy (parent interviewed, parent only filling in the questionnaire, and parent both interviewed and filling out the questionnaire). There were no significant differences between the three groups in any statistical measure.

The PHBQ study [1] was performed on 387 children (48\% response rate), aged from 6 mo to 16 y. The internal consistency (Cronbach's alpha) varied from 0.45 to 0.73 for factors and was 0.82 for the total score. The findings were that age, duration of hospital stay and social or occupational status (measured by type of hospital: private or not) were significantly related to one or more responses. Separation anxiety, sleep anxiety and aggression were the factors that showed significant relation to increased psychological upset after hospitalization as well as to the total score. Signs of psychological benefit were shown by $25 \%$ of the children.

\section{Aim}

The aim was to test the psychometric properties of the PHBQ and its relation to age and gender, in a Swedish translation, as well as whether it is a reliable and valid measurement instrument for behaviour changes in Swedish children, $36 \mathrm{y}$ after its introduction.

\section{Design}

The PHBQ was translated into Swedish using a backtranslation method. A medical consultant with English as a native language but speaking Swedish fluently performed the back-translation from Swedish into English. This person was unaware of the original version of the questionnaire. Discrepancies between the original version and the back translation were used to adjust the wording of the items. To test the use of the questionnaire, a small group of parents of hospitalized children answered the questionnaire and further adjustments were performed.

Children, $2-13$ (mean $7.0 \pm 2.9$ ) y of age, who were scheduled for an elective procedure that included anaesthesia, either because of surgery or for diagnostic purposes, were consecutively recruited. The exclusion criteria were oncological disease, mental retardation or parents who could not speak or understand Swedish. All children except 14 were treated at the University Hospital of Northern Sweden. The rest were from the Queen Silvia Child and Youth Hospital in Gothenburg.

The ethics committees at the universities of Umeå and Gothenburg approved the study.

Approximately $2 \mathrm{wk}$ before admittance, the parents were asked to complete a questionnaire concerning demographic data, number of earlier hospitalizations and anaesthesia. A short written form, including information about the hospital procedure, blood tests, premedication and anaesthesia, was sent to the parents at the same time.

Two weeks after returning home, the PHBQ questionnaire was sent to parents. If not answered within 1 wk, a reminder was sent.

Face validity was performed by a panel consisting of two child psychiatrists and two child psychologists. Face validity was use for exclusion of items and factor naming. Consensus was achieved.

\section{Patients and methods}

Data were collected during 2002 and 2003. Parents of 700 children were asked to participate in the study. Of those, 17 had already been in the study and were excluded, 14 were excluded due to the exclusion criteria and 55 were not admitted due to changes in medical indications for the procedure. This made 614 eligible for the study, and 168 refused participation, with a further 71 lost to follow-up due to administrative reasons (lost questionnaire). The remaining 375 received follow-up questionnaires, and, of those, 35 were never returned. This means that 340 participated fully in the study, and the response frequency was $55 \%$. Demographic data are shown in Table I. Individual answers for 64 items in 27 of the PHBQ questionnaires were missing $(0.8 \%)$. Item 4 had seven missing answers, which was the maximum number of missing data for any item. Two cases had several missing items but were included. Omitting those two cases did not change the results.

Mean length of hospitalization was $1.34 \mathrm{~d}(0-37$ d); $129(38.3 \%)$ were day cases. The mean length of stay for non-day care patients was $2.18 \mathrm{~d}$ (SD 4.2). 
Table I. Age and gender.

\begin{tabular}{|c|c|c|c|c|c|c|c|c|}
\hline & \multicolumn{4}{|c|}{ Boy } & \multicolumn{4}{|c|}{ Girl } \\
\hline & Mean & $n$ & $\%$ & $\mathrm{SD}$ & Mean & $n$ & $\%$ & SD \\
\hline Younger than $5 \mathrm{y}$ & 3.55 & 62 & $18.2 \%$ & 0.88 & 3.38 & 37 & $10.9 \%$ & 0.74 \\
\hline $5 \mathrm{y}$ and older & 8.35 & 140 & $41.2 \%$ & 2.16 & 8.47 & 101 & $29.7 \%$ & 2.16 \\
\hline Total & 6.87 & 202 & $59.4 \%$ & 2.90 & 7.10 & 138 & $40.6 \%$ & 2.94 \\
\hline
\end{tabular}

\section{Statistics}

Exploratory factor analysis and general statistics were analysed with SPSS 11.5. Confirmatory factor analysis was performed by structured equation modelling (AMOS 5.0, Smallwaters Corporation). Missing values in an item were replaced with a value randomly chosen and reflecting the distribution of the item.

\section{Results}

\section{Factor analysis}

Principal component analysis with Varimax rotation was used in the original study resulting in six factors. In this study, three different models were tested. From the original solution with six factors, one model was derived from exploratory factor analysis using Varimax rotation giving five factors, and a third model was derived using Oblimin rotation resulting in five factors with some differences in item distribution among the factors compared with Varimax rotation. Factor loadings greater than 0.4 were accepted. Two items (10: "Does your child need a lot of help doing things?" and 15: "Is it difficult to get your child to talk to you?") loaded poorly on any factor $(<0.4)$, and, when this was evaluated by an expert panel, they were omitted.

All three models were investigated according to fit to data using confirmative factor analysis. The model that fit the data best was that derived by the Oblimin rotation method. The factor loading in this model is shown in Table II. In this solution, the distribution of factor loading of the items differed substantially from the original model solution. Oblique rotation allows for correlation between factors, and these are shown in Table III.

The five factors accounted for $63.7 \%$ of the total variance. Factor I accounted for $39.7 \%$, factor II $7.2 \%$, factor III $6.6 \%$, factor IV $5.8 \%$ and factor V $4.4 \%$ of the variance.

The estimates of regression weights, variances and covariances for factors in the model based on Oblimin factor analysis were significant. One factor loaded only on three items resulting in an exact fit to data. In the original model, testing for factor 3 (separation anxiety) and factor 4 (eating disturbances), all estimates were non-significant.
When modifying the model by introducing error covariances between items, the model demonstrated good data fit. Since there is no consensus over which measure of fit is best, several measures are presented. The measures of fit in the original six-factor model and the five-factor model are shown in Table IV.

\section{Face validity}

The face validity panel agreed on omitting items 10 and 15 , and proposed the following names of the factors: I: general anxiety-withdrawal; II: eating disturbances; III: separation anxiety; IV: regressionaggression; V: sleep anxiety.

\section{Reliability}

The reliability was tested by using Cronbach's alpha, and was 0.92 for the total numbers of items, and $0.75-0.87$ for subscales (Table V).

\section{Influence of age}

It was found that age was correlated to the PHBQ score. Children with age less than $5 \mathrm{y}$ had significantly $(p<0.001)$ higher mean scores $(0.046 \pm 0.018)$ than older children $(-0.0089 \pm 0.014)$. This was true for all factors as well, except eating disturbances (factor 2) (Figure 1).

\section{Influence of gender}

Gender was not significantly correlated to the total PHBQ scores, nor to any of the factor scores (boys mean total PHBQ score $-0.0011 \pm 0.016$, girls $0.019 \pm 0.018)$. Even when controlling for age, this was true. The difference was nearly significant for eating disturbances (boys mean score $0.067 \pm 0.038$, girls $0.146 \pm 0.038, p=0.051$ ), as shown in Figure 2 .

\section{Discussion}

The results of this study support the psychometric properties of the translation and adaptation of the PHBQ. The findings indicate that the PHBQ has adequate reliability and that the measurements of fit for the factor structure were good in the tested 
Table II. Factor loadings in new solution after rotation and normalization.

\begin{tabular}{|c|c|c|c|c|c|c|c|c|}
\hline Item & Factor & Original factor & & 1 & 2 & 3 & 4 & 5 \\
\hline 3 & I & IV & Does your child spend time just sitting or lying and doing nothing? & 0.411 & 0.311 & & & \\
\hline 4 & & I & Does your child need a pacifier? & 0.732 & & & & \\
\hline 5 & & I & Does your child seem to be afraid of leaving the house without you? & 0.634 & & & & \\
\hline 6 & & I & Is your child uninterested in what goes on around him (or her)? & 0.738 & & & & \\
\hline 7 & & VI & Does your child wet the bed at night? & 0.780 & & & & \\
\hline 8 & & I & Does your child bite his (or her) finger nails? & 0.809 & & & & \\
\hline 11 & & VI & Is it difficult to get your child interested in doing things (like playing games, with toys and so on)? & 0.423 & 0.392 & & & \\
\hline 2 & II & IV & Does your child make a fuss about eating? & & 0.901 & & & \\
\hline 24 & & IV & Does your child have a poor appetite? & & 0.850 & & & \\
\hline 9 & III & II & Does your child get upset when you leave him (or her) alone for a few minutes? & & & 0.490 & & \\
\hline 12 & & I & Does your child seem to avoid or be afraid of new things? & 0.314 & & 0.525 & & \\
\hline 13 & & I & Does your child have difficulty making up his (or her) mind? & & & 0.464 & & \\
\hline 16 & & II & Does your child seem to get upset when someone mentions doctors or hospitals? & & & 0.727 & & \\
\hline 17 & & II & Does your child follow you everywhere around the house? & & & 0.573 & & \\
\hline 23 & & VI & Does your child seem to be shy or afraid around strangers? & & & 0.649 & & \\
\hline 18 & IV & II & Does your child spend time trying to get or hold your attention? & & & & -0.558 & \\
\hline 19 & & III & Is your child afraid of the dark? & & & 0.319 & -0.537 & \\
\hline 21 & & I & Is your child irregular in his (or her) bowel movements? & 0.326 & & & -0.436 & \\
\hline 25 & & $\mathrm{~V}$ & Does your child tend to disobey you? & & & & -0.817 & \\
\hline 26 & & VI & Does you child break toys or other objects? & & & & -0.897 & \\
\hline 27 & & I & Does your child suck his (or her) fingers or thumbs? & & & & -0.897 & \\
\hline 1 & $\mathrm{~V}$ & III & Does your child make a fuss about going to bed at night? & & & & & 0.826 \\
\hline 14 & & $\mathrm{~V}$ & Does your child have temper tantrums? & & & 0.366 & & 0.429 \\
\hline 20 & & II & Does your child have bad dreams or wake up and cry? & & & & & 0.488 \\
\hline 22 & & III & Does your child have trouble getting to sleep at night? & & & & & 0.658 \\
\hline
\end{tabular}

Factor loadings $<0.3$ are suppressed. Items 10 and 15 omitted. 
Table III. Correlation between factors.

\begin{tabular}{llcccc}
\hline Factor & & 1 & 2 & 3 & 4 \\
\hline I & General anxiety-withdrawal & 1.000 & & & \\
II & Eating disturbances & 0.245 & 1.000 & & \\
III & Separation anxiety & 0.820 & 0.309 & 1.000 & \\
IV & Regression-aggression & 0.681 & 0.261 & 0.699 & 1.000 \\
V & Sleep anxiety & 0.657 & 0.219 & 0.772 & 0.644 \\
\hline
\end{tabular}

$P<0.001$ for all correlations.

sample. The results support its use for further research.

The drop-out frequency in this study was quite high, partly due to administrative reasons (lost records). This was most likely a random process which should not, in our opinion, have influenced the sample in any systematic way. Reduction by this number (71) would raise the response frequency to $63 \%$. This exceeds the response rate of $48 \%$ in the original study [1].

Since the PHBQ is based on the sum of the value for different items, a positive answer could be hidden by a negative answer, i.e. the parent judgement of a new onset of behavioural change does not necessarily result in a change in the PHBQ score or in a factor score. Since the aim of this study is to investigate the factor structure, reliability, and the impact of gender and age, results concerning context validity are not presented. These types of data need to be presented in order to fully validate the PHBQ.

\section{Factor analyses}

Several models were tested with confirmative factor analysis using structured equation modelling. A fivefactor model solution emerged as the most consistent factor structure: factor I: general anxiety-withdrawal; factor II: eating disturbance; factor III: separation anxiety; factor IV: regression-aggression; and factor V: sleep anxiety. Two items (10 and 15) were excluded because of poor loading on any factor. Exclusion of these two items made the model better fit the data when using confirmative factor analysis. In the original study [1], three items (6, 7 and 16) were excluded due to relative low loading, and one (12) because of high loading (0.48) on two factors. These findings could not be replicated in this study.

The item distribution among factors is substantially different from the study by Vernon et al. [1]. Only anxiety-withdrawal, eating and sleeping disturbances have similarities (Table II).

The factor structure of the PHBQ is not always used. Some authors have used the factors $[6,7,17,18]$, but most use only the total score as a measure of behaviour change. In a meta-analysis, Vernon and Thomson only identified seven of 26 studies that used the factor subscales [2].

A factor analysis of the PHBQ in American children, using 1492 questionnaires and the Varimax rotation resulted in four factors accounting for $58.6 \%$ of the variance [25]. This is comparable with the cumulative variance $(59.2 \%)$ of factors $1-4$ in the present study. The item distribution among factors is not presented.

When using confirmative factor analysis, it is possible to calculate measures of fit of data to a proposed model. Both the original and the new model were tested, and in all measurements of fit it was possible to calculate, the new model performed better than the original one. In the original model, when testing for anxiety about sleep, it was not possible to find a complete model, as one of the errors or random influences for one item was found to have a variance that was negative.

\section{Internal consistency}

The internal consistency (Cronbach's alpha) for subscales was adequate $(0.81-0.87)$, and for the total score excellent (0.92). This is an improvement from the original validation procedure by Vernon (subscales $0.46-0.73$, total score 0.82 ).

\section{Influence of age}

Some studies have found that younger children had a greater change towards distress than older ones $[1,10,24]$. A meta-analysis [2] showed no relationship between age and PHBQ score, but the age distribution in the study samples did not allow for a firm conclusion concerning the age dependence of the PHBQ. Since many of the items in the questionnaire are connected to behaviours that are more frequent among younger children, the age influence may in part be related to the lack of questions that are related to behaviour and distress in older children. Further studies are needed to answer this question. 
Table IV. Measures of fit and significance of estimates for regression weight, variances and covariances for original and new model.

\begin{tabular}{|c|c|c|c|c|c|c|c|c|c|c|}
\hline Model & Factor & Name & NFI & GFI & RMSEA & TLI & $\chi^{2 / d f}$ & $p$ & $\begin{array}{l}\text { Significance of regression } \\
\text { weights and variances }\end{array}$ & Comment \\
\hline Original & I & General anxiety and regression & 0.986 & 0.986 & 0.033 & 0.992 & 1.371 & 0.158 & $p<0.05$ & Max. no. of covariances $6^{a}$ \\
\hline New & I & General anxiety-withdrawal & 0.992 & 0.992 & 0.000 & 1.001 & 0.967 & 0.470 & $p<0.001$ & Max. no. of covariances $4^{a}$ \\
\hline Original & II & Separation anxiety & 0.979 & 0.989 & 0.062 & 0.969 & 2.315 & 0.055 & $p<0.001$ & Max. no. of covariances $1^{a}$ \\
\hline New & III & Separation anxiety & 0.990 & 0.993 & 0.034 & 0.991 & 1.389 & 0.225 & $p<0.002$ & Max. no. of covariances $4^{a}$ \\
\hline Original & III & Anxiety about sleep & 1.000 & 1.000 & & & $\mathrm{df}=0$ & & $p=0.77$ & One variance negative ${ }^{c}$ \\
\hline New & $\mathrm{V}$ & Sleep anxiety & 0.839 & 0.959 & 0.034 & 0.792 & 2.831 & 0.249 & $p<0.01$ & \\
\hline Original & IV & Eating disturbance & 1 & 1 & & & $\mathrm{df}=0$ & $\begin{array}{l}\text { Could not be } \\
\text { computed }\end{array}$ & n.s. & \\
\hline New & II & Eating disturbance & & & & & & & & Underidentified ${ }^{\mathrm{b}}$ \\
\hline Original & $\mathrm{V}$ & Aggression toward authority & & & & & & & & Underidentified ${ }^{\mathrm{b}}$ \\
\hline New & IV & Regression-aggression & .994 & .993 & .031 & .996 & 1.327 & .249 & $\mathrm{P}<0.013$ & Max. no. of covariances $4^{a}$ \\
\hline Original & VI & Apathy-withdrawal & .985 & .992 & .037 & .988 & 1.469 & .184 & $\mathrm{P}<0.01$ & 3 covariances $^{a}$ \\
\hline $\begin{array}{l}\text { Desired values for } \\
\text { measures of fit. }\end{array}$ & & & $>0.90$ & & $<0.06$ & $>0.95$ & $<3.841$ & $>.05$ & & \\
\hline
\end{tabular}

${ }^{a}$ Numbers of added covariances between error or random influence of each item are described. These covariances will make the model fit data better.

b "Underidentified" means that there are not enough measured data (too few items) to identify a model for this factor.

${ }^{c}$ Variance of error influence was negative, which means that the model had problems with fitting the data.

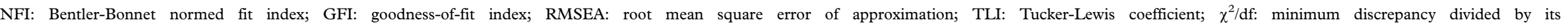
degrees of freedom.

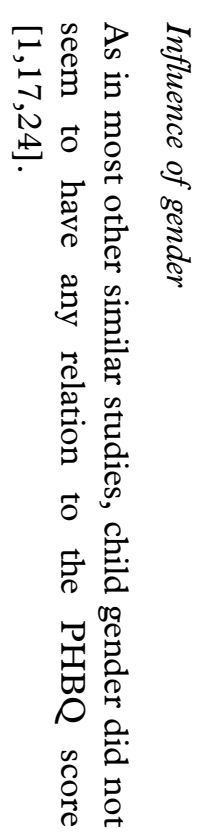
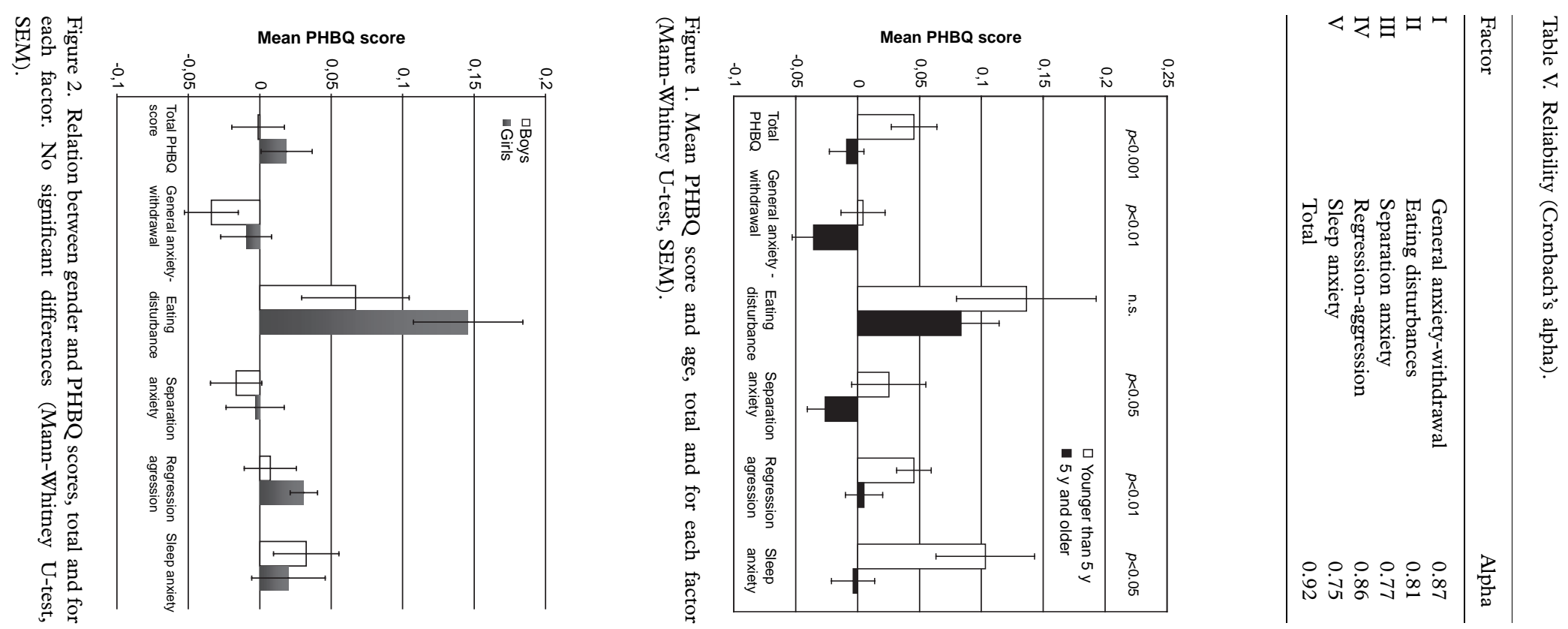


\section{Conclusion}

This study confirms that the Post Hospitalization Behavior Questionnaire in Swedish translation is reliable, and the presented factor structure fit the data well in the population that was tested here. Further validation of the instrument is warranted to find its relationship to previous hospitalizations and anaesthesias, number of children in the family, occupational and social status of the family, and possibly to compare the PHBQ scale with other measures of behavioural change.

\section{Acknowledgements}

This study was supported by a grant from Oscarsfonden and Insamlingsfonden from the University of Northern Sweden. The authors thank Karin Lundbäck and Minette Wilén for their work with data collection. We also thank Marie Johansson, Karin Nilsson and Krister Fredin for their assistance in the face validity judgement. For translation, we thank Rajiv Sharma.

\section{References}

[1] Vernon DT, Schulman JL, Foley JM. Changes in children's behavior after hospitalization. Some dimensions of response and their correlates. Am J Dis Child 1966;111:581-93.

[2] Thompson RH, Vernon DT. Research on children's behavior after hospitalization: a review and synthesis. J Dev Behav Pediatr 1993;14:28-35.

[3] Vernon DT, Thompson RH. Research on the effect of experimental interventions on children's behavior after hospitalization: a review and synthesis. J Dev Behav Pediatr 1993; $14: 36-44$.

[4] McGraw T, Kendrick A. Oral midazolam premedication and postoperative behaviour in children. Paediatr Anaesth 1998;8: $117-21$.

[5] Kain ZN, Mayes LC, Wang SM, Hofstadter MB. Postoperative behavioral outcomes in children: effects of sedative premedication. Anesthesiology 1999;90:758-65.

[6] Padfield NL, Twohig MM, Fraser AC. Temazepam and trimeprazine compared with placebo as premedication in children. An investigation extended into the first 2 weeks at home. Br J Anaesth 1986;58:487-93.

[7] Payne KA, Coetzee AR, Mattheyse FJ, Heydenrych JJ. Behavioural changes in children following minor surgery-is premedication beneficial? Acta Anaesthesiol Belg 1992;43: $173-9$.

[8] Margolis JO, Ginsberg B, Dear GL, Ross AK, Goral JE, Bailey AG. Paediatric preoperative teaching: effects at induction and postoperatively. Paediatr Anaesth 1998;8:17-23.
[9] Atkins DM. Evaluation of pediatric preparation program for short-stay surgical patients. J Pediatr Psychol 1987;12:28590.

[10] Visintainer MA, Wolfer JA. Psychological preparation for surgery pediatric patients: the effects on children's and parents' stress responses and adjustment. Pediatrics 1975;56: 187-202.

[11] Wolfer JA, Visintainer MA. Prehospital psychological preparation for tonsillectomy patients: effects on children's and parents' adjustment. Pediatrics 1979;64:646-55.

[12] Ferguson BF. Preparing young children for hospitalization: a comparison of two methods. Pediatrics 1979;64:656-64.

[13] Scaife JM, Campbell I. A comparison of the outcome of daycare and inpatient treatment of paediatric surgical cases. J Child Psychol Psychiatry 1988;29:185-98.

[14] Kay B. Outpatient anaesthesia, especially for children. Acta Anaesthesiol Scand Suppl 1966;25:421-5.

[15] Hannallah RS, Rosales JK. Experience with parents' presence during anaesthesia induction in children. Can Anaesth Soc J 1983;30:286-9.

[16] Vernon DT, Foley JM, Schulman JL. Effect of mother-child separation and birth order on young children's responses to two potentially stressful experiences. J Pers Soc Psychol 1967; 5:162-74.

[17] Kain ZN, Mayes LC, O'Connor TZ, Cicchetti DV. Preoperative anxiety in children. Predictors and outcomes. Arch Pediatr Adolesc Med 1996;150:1238-45.

[18] Kain ZN, Wang SM, Mayes LC, Caramico LA, Hofstadter MB. Distress during the induction of anesthesia and postoperative behavioral outcomes. Anesth Analg 1999;88:10427.

[19] McClowry SG. The relationship of temperament to pre- and posthospitalization behavioral responses of school-age children. Nurs Res 1990;39:30-5.

[20] McClowry SG, McLeod SM. The psychosocial responses of school-age children to hospitalization. Child Health Care 1990;19:155-61.

[21] Melnyk BM, Feinstein NF. Mediating functions of maternal anxiety and participation in care on young children's posthospital adjustment. Res Nurs Health 2001; 24:18-26.

[22] Davenport HT, Werry JS. The effect of general anesthesia, surgery and hospitalization upon the behavior of children. Am J Orthopsychiatry 1970;40:806-24.

[23] Cassell S. Effect of brief puppet therapy upon the emotional responses of children undergoing cardiac catheterization. J Consult Psychol 1965;29:1-8.

[24] Kotiniemi LH, Ryhanen PT, Moilanen IK. Behavioural changes following routine ENT operations in two-to-tenyear-old children. Paediatr Anaesth 1996;6:45-9.

[25] Kain ZN, Mayes LC, Caldwell-Andrews AA, Alexander GM, Krivutza D, Teague BA, et al. Sleeping characteristics of children undergoing outpatient elective surgery. Anesthesiology 2002;97:1093-101. 